\title{
Anisotropic Properties of Mesogenic Surfactants with Ionic Liquid Core
}

\author{
Jinzhi Wu, Masanori Nata and Seiji Ujiie*
}

\author{
Department of Applied Chemistry, Faculty of Engineering, Oita University, 700 Dannoharu, Oita 870-1192, \\ Japan
}

\begin{abstract}
HI-n), constructed from imidazolium-functionalized azobenzenes with differential flexible spacers and a nitro polar terminal group, were synthesized. Their potential thermotropic liquid crystal properties were investigated by polarizing optical microscopy (POM), differential scanning calorimetry (DSC) and temperature variable $X-$ ray diffraction measurements. HI- $\boldsymbol{n}$ exhibited a smectic A fluid (SmA) phase by anisotropy through interactions between azobenzene units and ionic interactions. This SmA formation was observed by POM and DSC. In the SmA phase, focal conic fan textures were observed by POM under the crossed-Nicols. The perpendicular structure (homeotropic alignment) formed spontaneously in the SmA phase through physical adsorption of imidazolium ionic units upon a glass plate. In the SmA phase, HI- $\boldsymbol{n}$ exhibited the X-ray diffraction patterns consisting of sharp inner reflections, corresponding to the layer distance, and a broad outer reflection exhibiting a short range order within the smectic layer. It is expected that the SmA layer consists of the hydrophilic and hydrophobic sublayers. The hydrophilic sublayer was formed by an ionic aggregation of imidazolium and iodide ions. On the other hand, the hydrophobic sublayer was obtained by segregation from the hydrophilic sublayer.

It can be considered that $\mathbf{H I}-\boldsymbol{n}$ are an anisotropic ionic liquid because the SmA state has a fluidity such as an ionic liquid. The ionic material shows the strong temperature dependence of an ionic interaction. The ionic interactions in the liquid crystal phase became weak gradually with increasing temperature, and the fluidity of the liquid crystal phase increase. $\mathbf{H I - n}$ dissolved in water. The HI- $\boldsymbol{n}$ water solution revealed a lyotropic smectic A anisotropic fluid.
\end{abstract}

Keywords: Anisotropic Fluid, Ionic Liquid Core, Ionic Liquid Crystal, Thermal Property, X-ray diffraction.

\section{INTRODUCTION}

It is well-known that ionic surface-active-agents (surfactants) form various lyotropic and thermotropic liquid-crystalline phases such as lamellar (smectic), columnar, and cubic fluid phases. The ionic surfactants exhibit the thermotropic liquid-crystalline phase through a microphase separation obtained by an ionic aggregation. The ionic surfactants were also used as a perpendicular alignment-treatment-agent for liquidcrystalline materials. In an alkylammonium halide (ionic surfactant), the ammonium ions reveal physical adsorption on glass plates, and the long alkyl chains of the alkylammonium are aligned perpendicular to the glass plates. The liquid-crystalline molecules are aligned along the long alkyl chains. Consequently, a perpendicular alignment (homeotropic structure) is formed. Ionic materials that the ionic surfactant unit is attached to an aromatic mesogenic group exhibit the thermotropic liquid-crystalline phases by anisotropy formed through interactions between the mesogenic groups as well as the ionic aggregation. Low-moecularweight and polymeric ionic mesogens with alkylammonium and piperidinium cores were reported [1-6]. In particular, the thermotropic ionic liquid crystal polymers were synthesized, and the validity of the ionic

*Address correspondence to this author at the Department of Applied Chemistry, Faculty of Engineering, Oita University, 700 Dannoharu, Oita 8701192, Japan; Tel: +81-97-554-7903; Fax: +81-97-554-7903;

E-mail: seujiiie@oita-u.ac.jp interaction was revealed [2]. The structure of the ionic unit influences phase transitions and orientational behavior of ionic liquid-crystalline materials [7-9]. These liquid crystals exhibited a smectic A fluid phase with enhanced thermal stability, having hydrophilic and hydrophobic sublayers. Moreover, the introduction of a hydroxyl group in the ionic group acted effectively in forming the liquid-crystalline phase. In addition, ionic groups such as alkylammonium, pyridinium, and imidazolium ions are used as cores of ionic liquids. These ionic liquids can be used as a solvent for a chemical reaction. It is expected that the combination of an aromatic mesogenic group and an ionic liquid core leads to the formation of fluids with anisotropic properties.

In this study, we synthesized ionic liquid-crystalline compounds, having an imidazolium ionic liquid core with a hydroxyl group and a mesogenic group, and examined their thermal and orientational properties. This paper describes an effect of ionic interactions and an anisotropy in the thermotropic ionic liquid crystals. Moreover, anisotropic properties of a solution of the ionic liquid crystal were examined.

\section{METHODS}

\subsection{Synthesis}

The structures of intermediates $\mathrm{Br}-\boldsymbol{n}(n=6 \sim 9)$ and ionic compounds HI-n $(n=6 \sim 9)$ are presented in 

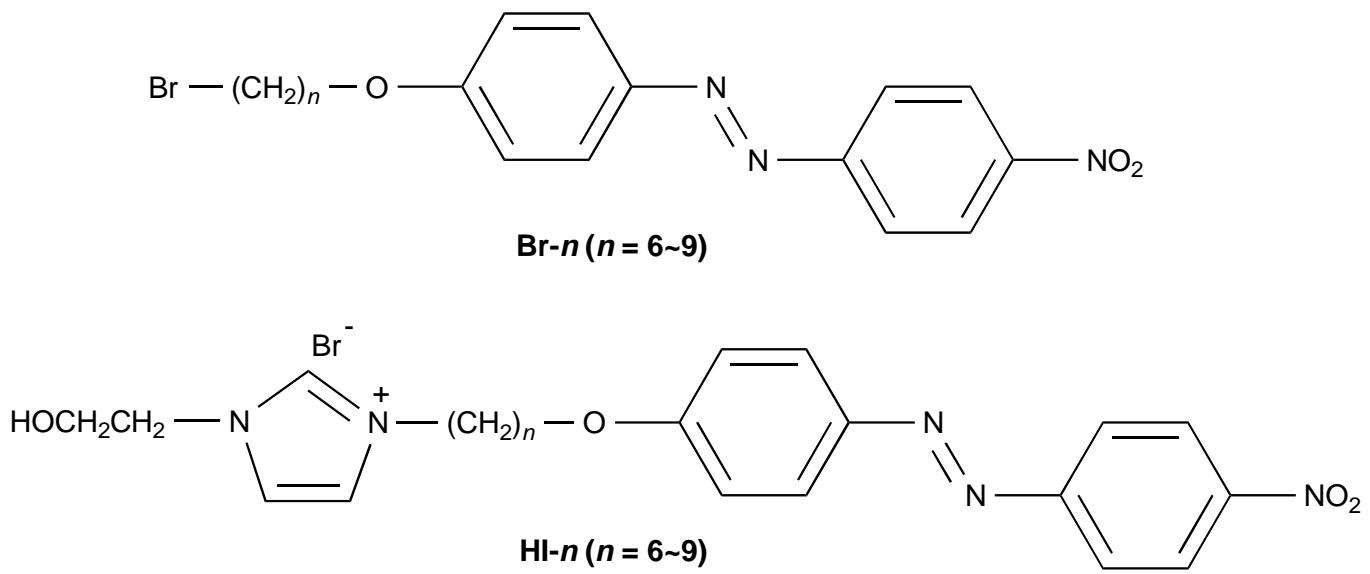

Figure 1: Structures of $\mathbf{B r}-\boldsymbol{n}(n=6 \sim 9)$ and $\mathbf{H I}-\boldsymbol{n}(n=6 \sim 9)$.

Figure 1. The fundamental analytical data by which the obtained products are characterized are shown below.

\section{6-bromo-1-(4-(4-(nitro)phenylazo)phenoxy)hexane (Br-6)}

4-(4-(Nitro)phenylazo)phenol $(5.00 \mathrm{~g}, 20.56 \mathrm{mmol})$, 1,6-dibromohexane (15.35 g, $62.92 \mathrm{mmol})$, and anhydrous potassium carbonate $\left(\mathrm{K}_{2} \mathrm{CO}_{3}: 4.28 \mathrm{~g}, 30.97\right.$ $\mathrm{mmol}$ ) were added to acetone $(400 \mathrm{~mL})$ under magnetic stirring, and the reaction mixture was heated to $80{ }^{\circ} \mathrm{C}$ and refluxed for $64 \mathrm{~h}$. After the reaction was completed, the hot solution was immediately filtered off and the inorganic residues were washed thoroughly with acetone. The filtrates were collected and distilled under vacuum to remove acetone. The residues were dissolved in chloroform. The resulting chloroform solution and distilled water were added to a separating funnel and shaken vigorously to remove any excess of potassium carbonate and potassium bromide generated during the reaction until the water phase became neutral. The chloroform layer was dried over anhydrous magnesium sulfate to remove any water remaining in the solution. After removal of the solvent by reduced pressure distillation, the precipitated product was recrystallized from hexane. Dried under vacuum to get $5.56 \mathrm{~g}$ of red crystals. Yield: $66.6 \%$. ${ }^{1} \mathrm{H}$ $\operatorname{NMR}\left(\mathrm{CDCl}_{3}\right), \delta: 1.53-1.55\left(4 \mathrm{H},-\mathrm{CH}_{2}-\right), 1.84-1.94(4 \mathrm{H}$, $\left.-\mathrm{CH}_{2^{-}}\right)$, 3.43-3.46 (2H, Br- $\left.\mathrm{CH}_{2^{-}}\right)$, 4.06-4.09 $\left(2 \mathrm{H},-\mathrm{CH}_{2^{-}}\right.$ O-phenyl), 7.02-7.04 (2H, phenyl), 7.96-8.00 (4H, phenyl), 8.36 (2H, phenyl).

\section{7-bromo-1-(4-(4-(nitro)phenylazo)phenoxy)heptane (Br-7)}

Yield: $78.7 \%$. ${ }^{1} \mathrm{H}$ NMR $\left(\mathrm{CDCl}_{3}\right), \delta: 1.39-1.54(6 \mathrm{H}$, $\left.\mathrm{CH}_{2^{-}}\right)$, 1.81-1.94 (4H, $\left.-\mathrm{CH}_{2^{-}}\right), 3.39-3.44\left(2 \mathrm{H}, \mathrm{Br}^{-} \mathrm{CH}_{2^{-}}\right)$, 4.05-4.08 (2H, $-\mathrm{CH}_{2}$-O-phenyl), 7.01-7.04 (2H, phenyl), 7.95-8.00 (4H, phenyl), 8.34-8.36 (2H, phenyl).

\section{8-bromo-1-(4-(4-(nitro)phenylazo)phenoxy)octane (Br-8)}

Yield: $71.4 \% .{ }^{1} \mathrm{H}$ NMR $\left(\mathrm{CDCl}_{3}\right), \delta: 1.37-1.53(8 \mathrm{H}$, $\left.\mathrm{CH}_{2^{-}}\right)$, 1.80-1.89 (4H, $\left.-\mathrm{CH}_{2^{-}}\right), 3.41-3.44\left(2 \mathrm{H}, \mathrm{Br}^{-} \mathrm{CH}_{2^{-}}\right)$, 4.05-4.08 (2H, - $\mathrm{CH}_{2}$-O-phenyl), 7.02-7.04 (2H, phenyl), 7.95-8.00 (4H, phenyl), 8.36-8.38 (2H, phenyl).

\section{9-bromo-1-(4-(4-(nitro)phenylazo)phenoxy)nonane (Br-9)}

Yield: $84.0 \%$ \%. ${ }^{1} \mathrm{H}$ NMR $\left(\mathrm{CDCl}_{3}\right), \delta: 1.43-1.56(10 \mathrm{H},-$ $\left.\mathrm{CH}_{2^{-}}\right), 1.82-1.88\left(4 \mathrm{H},-\mathrm{CH}_{2^{-}}\right), 3.40-3.43\left(2 \mathrm{H}, \mathrm{Br}-\mathrm{CH}_{2^{-}}\right)$, 4.05-4.08 (2H, - $\mathrm{CH}_{2}$-O-phenyl), 7.02-7.26 (2H, phenyl), 7.95 (4H, phenyl), 8.35-8.38 (2H, phenyl).

\section{1-(2-hydroxyethyl)-3-(6-(4-(4-(nitro)phenylazo) phenoxy)hexyl)imidazolium bromide (HI-6)}

Br-6 (1.00 g, $2.46 \mathrm{mmol})$, and 1-(2hydroxyethyl)imidazole $(0.31 \mathrm{~g}, 2.76 \mathrm{mmol})$ were dissolved in $30 \mathrm{~mL}$ of 2-propanol, and the mixed solution was reacted at $120{ }^{\circ} \mathrm{C}$ for $117 \mathrm{~h}$. After the reaction, the mixed solution was evaporated under vacuum. Yield: $90.6 \%$. ${ }^{1} \mathrm{H}$ NMR $\left(\mathrm{CDCl}_{3}\right), \delta: 1.46-1.61$ $\left(4 \mathrm{H},-\mathrm{CH}_{2^{-}}\right), 1.84-1.87\left(2 \mathrm{H},-\mathrm{CH}_{2^{-}}\right), 1.99-2.03(2 \mathrm{H}$, $\left.\mathrm{CH}_{2-}^{-}\right), 2.62(1 \mathrm{H},-\mathrm{OH}), 4.01-4.09\left(4 \mathrm{H}, \mathrm{HO}-\mathrm{CH}_{2}^{-} ;-\mathrm{CH}_{2-}\right.$ O-phenyl), 4.28-4.32 (2H, N-CH $\left.\mathrm{CH}_{2}\right), 4.50-4.52\left(2 \mathrm{H}, \mathrm{N}^{+}\right.$$\left.\mathrm{CH}_{2}-\right)$, 7.01-7.04 (2H, phenyl), 7.23-7.24 $(1 \mathrm{H},-\mathrm{CH}=\mathrm{CH}-$ $\mathrm{N}^{+}$, imidazole), 7.39-7.40 $(1 \mathrm{H}, \mathrm{N}-\mathrm{CH}=\mathrm{CH}$-, imidazole $)$, 7.95-8.00 (4H, phenyl), 8.34-8.38 (2H, phenyl), 9.90 $\left(1 \mathrm{H}, \mathrm{N}-\mathrm{CH}=\mathrm{N}^{+}\right.$, imidazole $)$.

\section{1-(2-hydroxyethyl)-3-(7-(4-(4-(nitro)phenylazo )phenoxy)heptyl)imidazolium bromide (HI-7)}

Yield: $82.6 \%$ \% ${ }^{1} \mathrm{H}$ NMR $\left(\mathrm{CDCl}_{3}\right), \delta: 1.35-1.50(8 \mathrm{H}$, $\left.\mathrm{CH}_{2^{-}}\right)$, 1.80-1.95 (2H, - $\left.\mathrm{CH}_{2^{-}}\right)$, 3.90-4.06 (2H, $\left.\mathrm{HO}-\mathrm{CH}_{2^{-}}\right)$, 4.20-4.30 (2H, - $\mathrm{CH}_{2}$-O-phenyl), 4.49-4.52 (2H, N-CH ${ }_{2}-$, $4.67\left(2 \mathrm{H}, \mathrm{N}^{+}-\mathrm{CH}_{2^{-}}\right), 6.10(1 \mathrm{H},-\mathrm{OH}), 7.00-7.02(2 \mathrm{H}$, phenyl), 7.34-7.35 (1H, $-\mathrm{CH}=\mathrm{CH}-\mathrm{N}^{+}$, imidazole), 7.59- 
$7.60(1 \mathrm{H}, \quad \mathrm{N}-\mathrm{CH}=\mathrm{CH}-$, imidazole $), 7.93-8.04 \quad(4 \mathrm{H}$, phenyl), 8.33-8.36 $\left(2 \mathrm{H}\right.$, phenyl), $9.76\left(1 \mathrm{H}, \mathrm{N}-\mathrm{CH}=\mathrm{N}^{+}\right.$, imidazole).

\section{1-(2-hydroxyethyl)-3-(8-(4-(4-(nitro)phenylazo) phenoxy)octyl)imidazolium bromide (HI-8)}

Yield: $85.7 \% .{ }^{1} \mathrm{H}$ NMR $\left(\mathrm{CDCl}_{3}\right), \delta: 1.21-1.50(8 \mathrm{H},-$ $\left.\mathrm{CH}_{2^{-}}\right), 1.79-1.86\left(2 \mathrm{H},-\mathrm{CH}_{2^{-}}\right), 1.93-1.96\left(2 \mathrm{H},-\mathrm{CH}_{2^{-}}\right)$, $2.62(1 \mathrm{H},-\mathrm{OH}), 3.99-4.01\left(2 \mathrm{H}, \mathrm{HO}-\mathrm{CH}_{2}-\right), 4.04-4.08$ (2H, - $\mathrm{CH}_{2}$-O-phenyl), 4.24-4.28 (2H, N-CH $\left.2^{-}\right), 4.50-4.52$ $\left(2 \mathrm{H}, \mathrm{N}^{+}-\mathrm{CH}_{2^{-}}\right), 6.99-7.03(2 \mathrm{H}$, phenyl), 7.21-7.24 $(1 \mathrm{H},-$ $\mathrm{CH}=\mathrm{CH}-\mathrm{N}^{+}$, imidazole $), \quad 7.45-7.46 \quad(1 \mathrm{H}, \quad \mathrm{N}-\mathrm{CH}=\mathrm{CH}-$, imidazole), $7.95-8.00(4 \mathrm{H}$, phenyl), 8.34-8.38 $(2 \mathrm{H}$, phenyl), $9.84\left(1 \mathrm{H}, \mathrm{N}-\mathrm{CH}=\mathrm{N}^{+}\right.$, imidazole $)$.

\section{1-(2-hydroxyethyl)-3-(9-(4-(4-(nitro)phenylazo) phenoxy)nonyl)imidazolium bromide (HI-9)}

Yield: $80.8 \%$ \%. ${ }^{1} \mathrm{H}$ NMR $\left(\mathrm{CDCl}_{3}\right), \delta: 1.36-1.50(10 \mathrm{H},-$ $\left.\mathrm{CH}_{2^{-}}\right), 1.79-1.86\left(2 \mathrm{H},-\mathrm{CH}_{2^{-}}\right), 1.93-1.95\left(2 \mathrm{H},-\mathrm{CH}_{2^{-}}\right)$, $2.91(1 \mathrm{H},-\mathrm{OH}), 3.92-4.01\left(2 \mathrm{H}, \mathrm{HO}-\mathrm{CH}_{2}-\right), 4.04-4.07$ (2H, - $\mathrm{CH}_{2}-\mathrm{O}-$-, phenyl), 4.23-4.26 (2H, N-CH- - 4.49 $4.51\left(2 \mathrm{H}, \mathrm{N}^{+}-\mathrm{CH}_{2^{-}}\right)$, 6.99-7.04 (2H, phenyl), 7.21-7.23 $\left(1 \mathrm{H}, \quad-\mathrm{CH}=\mathrm{CH}-\mathrm{N}^{+}, \quad\right.$ imidazole $), \quad 7.42-7.44 \quad(1 \mathrm{H}, \quad \mathrm{N}-$ $\mathrm{CH}=\mathrm{CH}$-, imidazole), 7.94-8.00 (4H, phenyl), 8.34-8.38 $\left(2 \mathrm{H}\right.$, phenyl), $9.83\left(1 \mathrm{H}, \mathrm{N}-\mathrm{CH}=\mathrm{N}^{+}\right.$, imidazole $)$.

\subsection{Measurements}

Phase transitions were measured using a Shimadzu DSC60 and a Nikon polarizing microscope (ECLIPSE LV100POL) with a Mettler FP82 hot stage apparatus equipped with a Mettler FP90 controller. The DSC measurements were performed by scan rate of 10 ${ }^{\circ} \mathrm{C} / \mathrm{min}$. The X-ray diffractions were measured with a Shimadzu XRD-6100-TTK450 by using a Cu-Ka radiation. The $\mathrm{X}$-ray diffraction measurements were performed at a mesomorphic temperature range.

\section{RESULTS AND DISCUSSION}

\subsection{Formation of Anisotropic Fluid and Phase Transitions}

The phase transition temperatures of the intermediates $\mathrm{Br}-\boldsymbol{n}(n=6-9)$ are summarized in Table 1. Br-6, Br-8 and Br-9 did not exhibit a liquid-crystalline phase on heating and cooling, whereas Br-7 exhibited a nematic fluid phase (monotropic liquid crystal) on cooling.

HI-n $(n=6-9)$ that an imidazolium core with 2hydroxyethyl group attaches to a nitroazobenzene mesogenic group through a methylene chain revealed
Table 1: Phase Transitions of Br-n

\begin{tabular}{|c|c|c|}
\hline \multirow{2}{*}{$\mathbf{n}$} & \multicolumn{2}{|c|}{ Phase transition temp. ${ }^{1}{ }^{\circ} \mathbf{C}\left(\Delta \mathbf{H} / \mathbf{~ k J m o l}^{-1}\right)^{2}$} \\
\cline { 2 - 3 } & heating & cooling \\
\hline \hline 6 & $\mathrm{k} 89.7(2.4) \mathrm{I}$ & $\mathrm{I} 73.4(2.3) \mathrm{k}$ \\
\hline 7 & $\mathrm{k} 85.0(28.4) \mathrm{I}$ & $\mathrm{I} 71.5(27.3) \mathrm{k}$ \\
\hline 8 & $\mathrm{k} 76.0(37.8) \mathrm{I}$ & $\mathrm{I} 66.8(-) \mathrm{N} 57.0(36.7) \mathrm{k}$ \\
\hline 9 & $\mathrm{k} 96.7(48.6) \mathrm{I}$ & $\mathrm{I} 78.1(48.5) \mathrm{k}$ \\
\hline
\end{tabular}

$\mathrm{k}$ : solid, N: nematic, I: isotropic.

phase transition enthalpy.

solid-smectic and smectic-isotropic phase transitions. The phase transition temperatures of $\mathbf{H I}-\boldsymbol{n}$ are summarized in Table 2. HI- $\boldsymbol{n}$ exhibited a smectic A fluid (SmA) phase with a focal conic fan texture (Figure 2). HI-n also showed a dark field exhibiting a perpendicular alignment, which is characterized by an interference figure obtained through the conoscopic observation (Figure 3). The alkyl spacer chain length of HI- $\boldsymbol{n}$ influenced the phase transitions. The SmAisotropic phase transition temperatures of evenmembered $\mathbf{H I}-\boldsymbol{n}$ with $n=6$ and 8 are higher when compared to odd-membered $\mathbf{H I}-n$ with $n=7$ and 9 (Figure 4). Phase transition enthalpies of $\mathbf{H I}-n$ also revealed an even-odd effect as shown in Figure 5. This indicates that even membered $\mathbf{H I}-\boldsymbol{n}$ have a higher thermal stability of the SmA orientational structure than odd membered HI- $\boldsymbol{n}$.

Table 2: Phase Transitions of HI-n

\begin{tabular}{|c|c|}
\hline \multirow{2}{*}{$\mathbf{n}$} & Phase transition temperatures ${ }^{1} /{ }^{\circ} \mathbf{C}$ \\
\hline \hline \multirow{2}{*}{6} & (heating) k 52.7 SmA 193.3 I \\
\cline { 2 - 2 } & (cooling) I 187.3 SmA 35.9 k \\
\hline \multirow{2}{*}{7} & (heating) k 44.0 SmA 150.2 I \\
\cline { 2 - 2 } & (cooling) I 140.0 SmA 28.5 k \\
\hline \multirow{2}{*}{8} & (heating) k 60.8 SmA 185.0 I \\
\cline { 2 - 2 } & (cooling) I 174.9 SmA 42.4 k \\
\hline \multirow{2}{*}{9} & (heating) k 51.3 SmA 166.9 I \\
\cline { 2 - 2 } & (cooling) I 158.2 SmA 40.6 k \\
\hline
\end{tabular}

${ }^{1} \mathrm{k}$ : solid, SmA: smectic A, I: isotropic.

In general, ionic liquid crystals are a kind of a surfactant. For example, the ionic liquid crystals can dissolve in water, and the lyotropic liquid crystal system is produced [10]. Furthermore, the ionic liquid crystals can dissolve poly(vinyl alcohol) as a solvent [11]. Anisotropic properties of a water solution of $\mathbf{H I}-\boldsymbol{n}$ were examined by a contact test method. HI- $\boldsymbol{n}$ with the imidazolium core with 2-hydroxyethyl group dissolved 


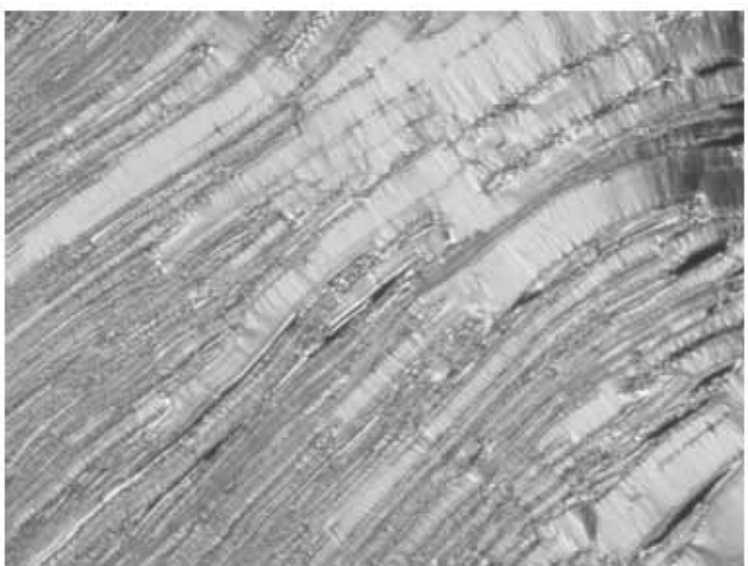

$119.6{ }^{\circ} \mathrm{C}$

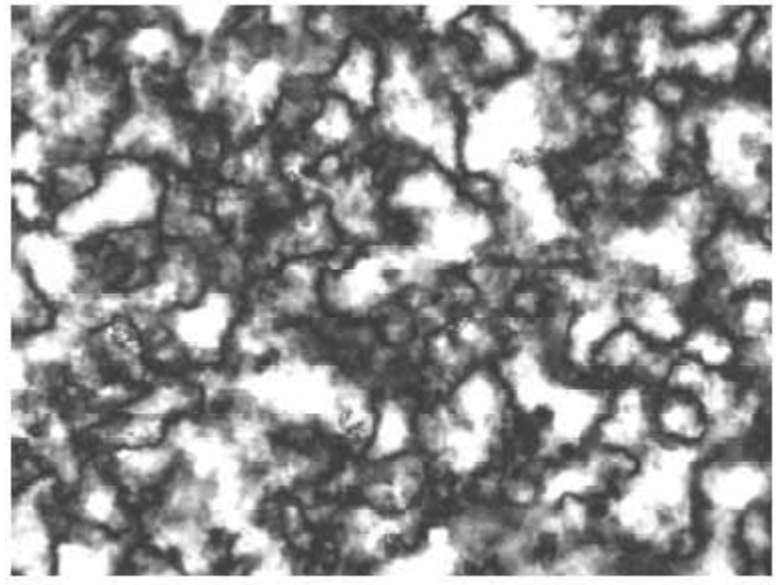

\section{$44.1{ }^{\circ} \mathrm{C}$}

Figure 2: Fan texture of smectic A fluid $\left(119.6{ }^{\circ} \mathrm{C}\right)$ and crystal $\left(44.1^{\circ} \mathrm{C}\right)$ of $\mathbf{H I}-6$.

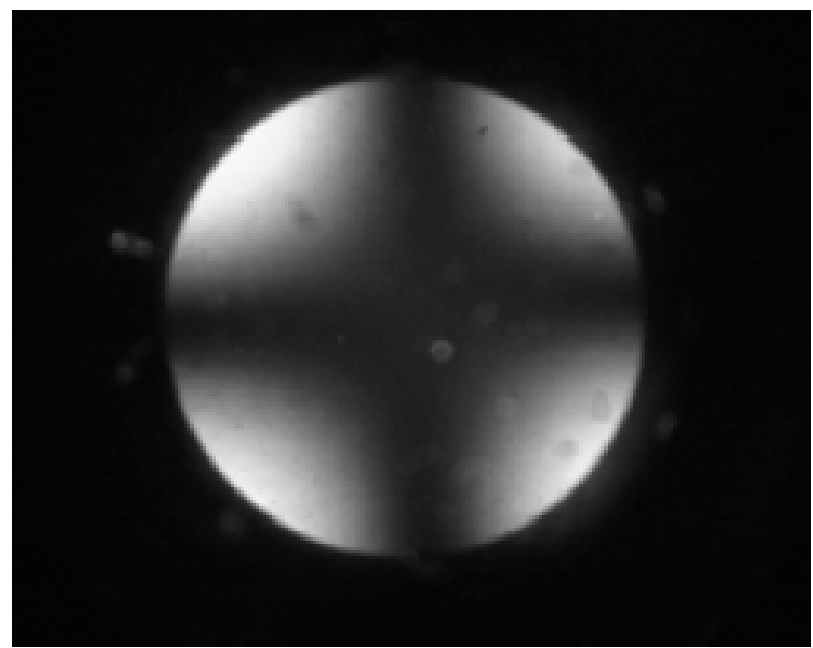

Figure 3: Conoscopic figure observed for perpendicular alignment of $\mathrm{HI}-8$ at $74.0 \mathrm{C}$.

in water. Mixtures consisting of water $\mathbf{H I - 7}$ and $\mathrm{HI}-9$ formed an oilystreak texture exhibiting the formation of SmA orientational structure, as shown in Figure 6.

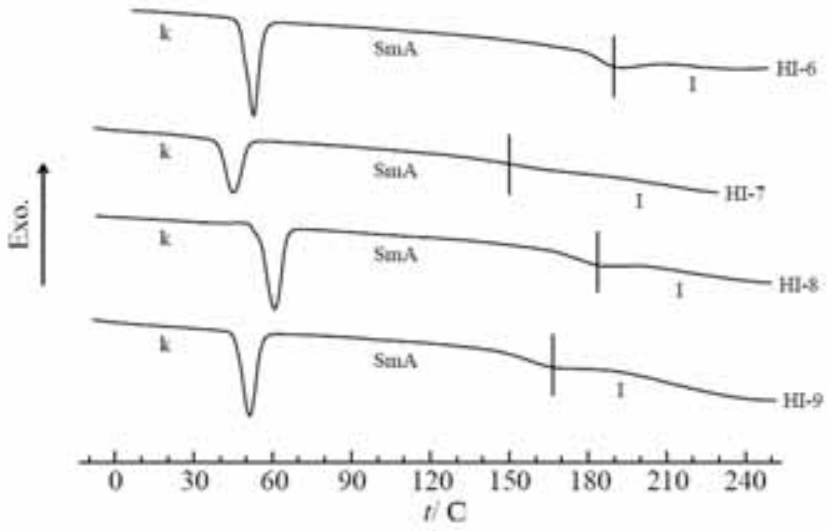

heating

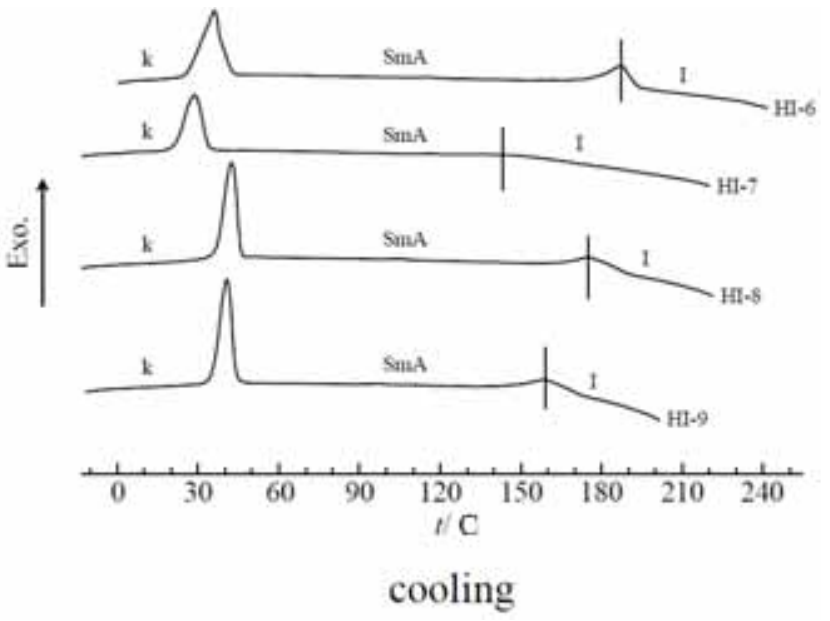

Figure 4: DSC curves of $\mathrm{HI}-\boldsymbol{n}(n=6 \sim 9)$.

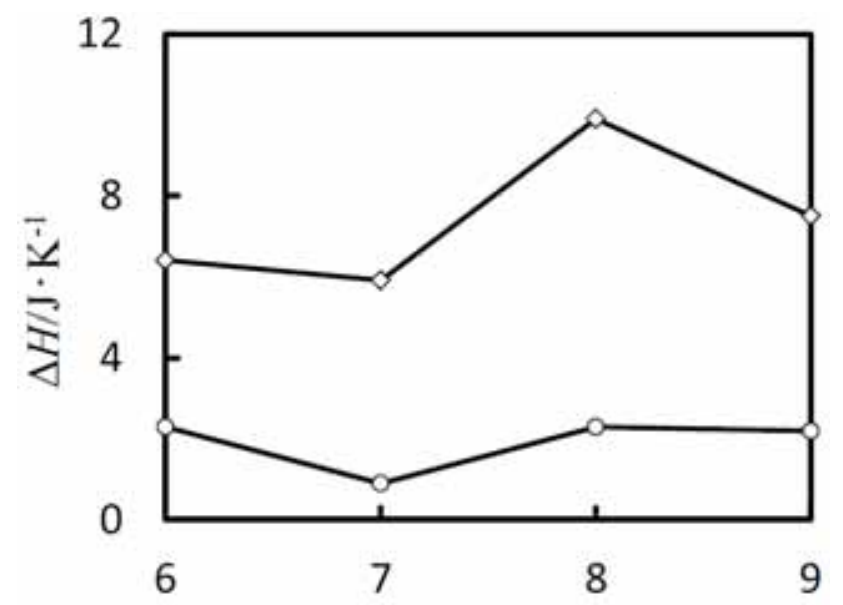

Figure 5: Phase transition enthalpies $(\Delta H)$ of $\mathbf{H I}-\boldsymbol{n}$. Circle symbol: solid-SmA phase transition entropy; Square symbol: SmA-isotropic phase transition entropy.

\subsection{Anisotropic Orientational Behavior}

More direct information about the orderings in $\mathbf{H I}-\boldsymbol{n}$ with $n=6 \sim 9$ can be obtained by the X-ray diffraction measurement. The angles of the $\mathrm{X}$-ray diffraction peak maxima and associated layer spacings are given in 


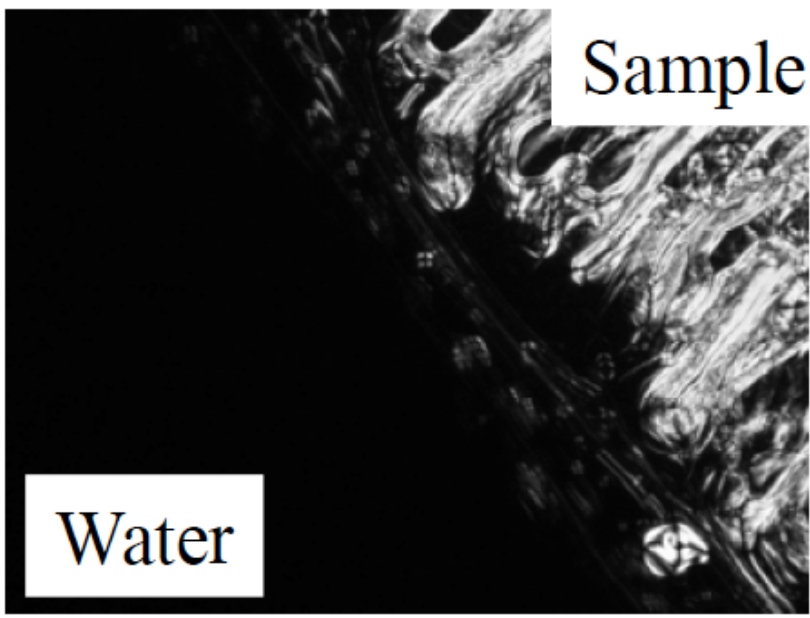

A
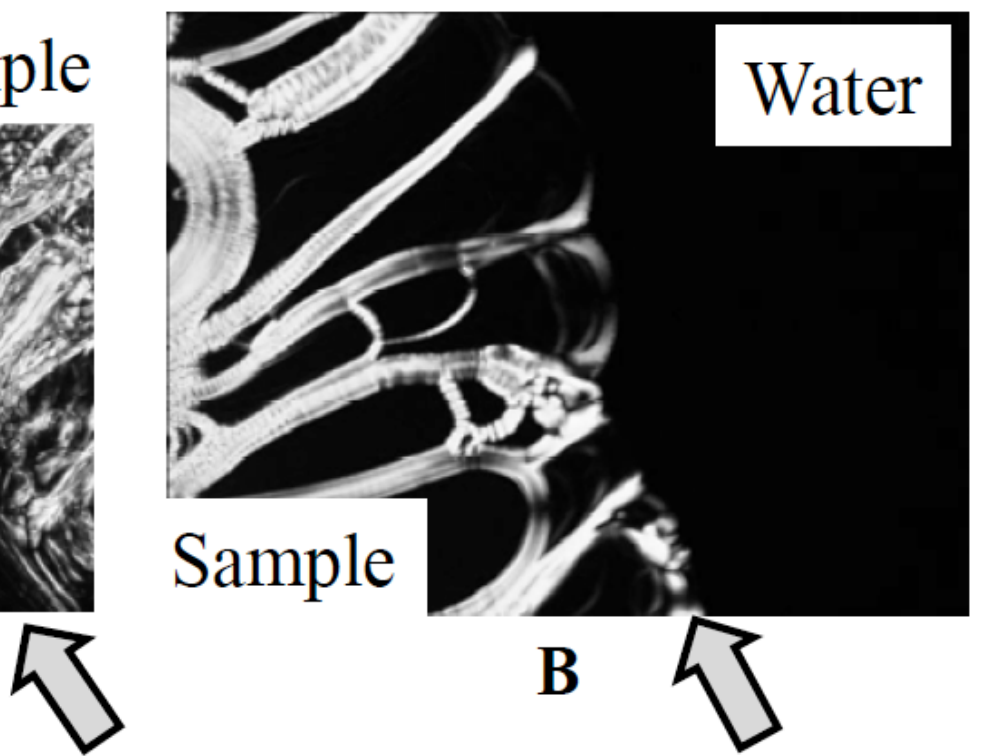

Figure 6: Contact test of water and $\mathrm{HI}-n$ with $n=7$ and 9. A: $\mathrm{HI}-7,70{ }^{\circ} \mathrm{C}$; $\mathrm{B}$ : HI-9, $70{ }^{\circ} \mathrm{C}$. Arrows indicate contact areas of water and $\mathrm{HI}-\boldsymbol{n}$ with $n=7$ and 9 .

Table 3: X-Ray Data of HI-n

\begin{tabular}{|c|c|c|c|c|}
\hline \multirow{2}{*}{ Sample } & \multicolumn{2}{|c|}{ X-ray reflections } & \multirow{2}{*}{ Extended molecular length $(L) / \mathrm{nm}$} & \multirow{2}{*}{ Temp. $/{ }^{\circ} \mathrm{C}$} \\
\hline & $2 \theta /$ degree & Spacing $(d) / \mathrm{nm}$ & & \\
\hline \multirow{4}{*}{ HI-6 } & 2.9 & 3.04 & \multirow{4}{*}{2.64} & \multirow{4}{*}{100} \\
\hline & 5.7 & 1.55 & & \\
\hline & 8.5 & 1.04 & & \\
\hline & 11.3 & 0.78 & & \\
\hline \multirow{4}{*}{$\mathrm{HI}-7$} & 2.4 & 3.64 & \multirow{4}{*}{2.76} & \multirow{4}{*}{100} \\
\hline & 4.7 & 1.89 & & \\
\hline & 6.9 & 1.27 & & \\
\hline & 9.3 & 0.95 & & \\
\hline \multirow{4}{*}{ HI-8 } & 2.6 & 3.35 & \multirow{4}{*}{2.88} & \multirow{4}{*}{100} \\
\hline & 5.2 & 1.71 & & \\
\hline & 7.6 & 1.16 & & \\
\hline & 10.2 & 0.87 & & \\
\hline \multirow{4}{*}{ HI-9 } & 2.5 & 3.51 & \multirow{4}{*}{3.01} & \multirow{4}{*}{100} \\
\hline & 4.9 & 1.81 & & \\
\hline & 7.3 & 1.21 & & \\
\hline & 9.7 & 0.91 & & \\
\hline
\end{tabular}

Table 3. The extended molecular lengths were obtained by using both a space-filing model and chem3D. In general, the X-ray diffraction pattern for a SmA phase consists of the sharp inner reflections and the broad outer reflection. The X-ray diffraction patterns were measured for the anisotropic samples of $\mathbf{H I}-\boldsymbol{n}$ ( $n=$ 6 9). They all display the X-ray diffraction patterns consisting of four inner reflections and the outer broad halo. The spacings obtained from the first order reflection indicate a layer thickness of $3.00 \sim 3.70 \mathrm{~nm}$ for HI-n $(n=6 \sim 9)$. Regarding the X-ray diffraction pattern of $\mathrm{HI}-7$ in Figure $7\left(100{ }^{\circ} \mathrm{C}\right)$, the distinct maximum centered at $2.4^{\circ}$ corresponds to a spacing of $3.64 \mathrm{~nm}$, while the extended molecular length of $\mathbf{H I - 7}$ is $2.76 \mathrm{~nm}$. The ratio of the reciprocal of spacings $\left(1 / d_{1}, 1 / d_{2}, 1 / d_{3}\right.$, $\left.1 / d_{4}\right)$ obtained from four inner reflections have a 
relation of $1: 2: 3: 4$. The X-ray diffraction patterns of $\mathrm{HI}-\boldsymbol{n}$ with $n=6,8,9$ resemble that of $\mathrm{HI}-7$, showing the presence of the SmA phase. The layer spacing of the SmA phase is a value longer than the molecular length but shorter than twice the molecular length. This result indicates that $\mathbf{H I}-\boldsymbol{n}$ exhibit a partial bilayer type of the SmA phase consisting of the hydrophilic and hydrophobic sublayers. Those sublayers alternately pile in the SmA phase. A possible packing model is schematically illustrated in Figures $\mathbf{8}$. In the hydrophilic sublayers, hydrogen bondings and ionic interactions are formed by hydroxyl, imidazolium ion and bromide ion groups. These interactions enhanced the thermal stabilization of the hydrophilic sublayer.

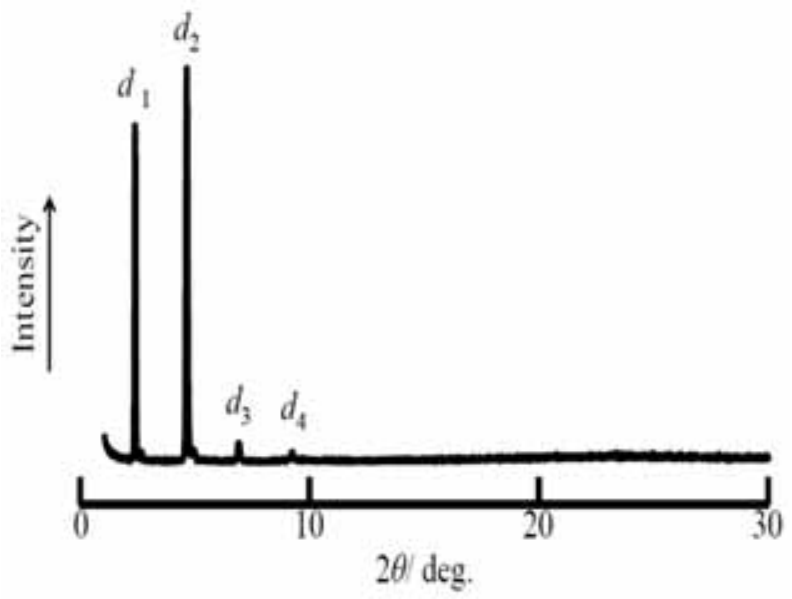

Figure 7: X-ray diffraction pattern of smectic A phase of HI-7 at $100.0 \mathrm{C}$.

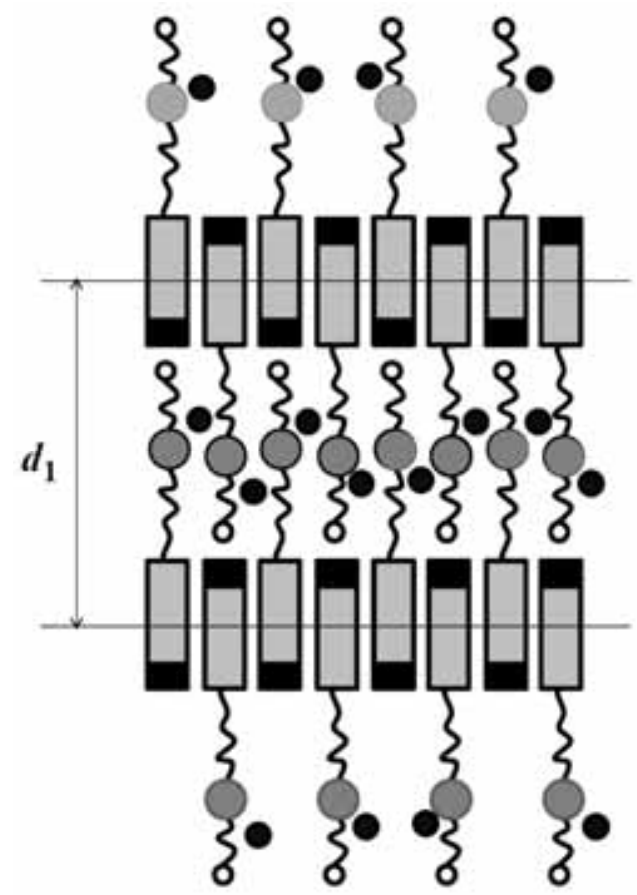

Figure 8: Possible packing model of smectic A phases of HIn.

\section{CONCLUSIONS}

The ionic liquid crystals (HI-n, $n=6 \sim 9$ ) and the water solutions of $\mathbf{H I - n}$ clearly formed the SmA phase. The liquid crystal formation of HI- $\boldsymbol{n}$ is led by the ionic aggregation and anisotropy between azobenzene rodlike groups. The SmA phase of $\mathbf{H I} \boldsymbol{n}$ has a layer structure consisting of hydrophilic and hydrophobic sublayers. The hydrophilic sublayer is formed by the aggregation of ionic and hydroxyl groups. On the other hand, the azobenzene groups are aligned and formed the hydrophobic sublayer. The X-ray diffraction patterns revealed the existence in high layer periodicity of the SmA phase because the first, second, third and fourth inner reflections were observed at the X-ray small-angles. In the mixtures of water and $\mathbf{H I}-\boldsymbol{n}, \mathrm{H}_{2} \mathrm{O}$ molecules are located within the hydrophilic sublayer of $\mathbf{H I} \boldsymbol{n}$. It is expected that $\mathbf{H I - n}$ can act as a solubilizing agent of a hydrophilic polymer such as poly(vinyl alcohol) and cellulose derivatives [10-12].

\section{REFERENCES}

[1] Ujiie S, limura K. Ammonium Halide Type Thermotropic Liquid-Crystalline Polyethyleneimines and Those Low-Mass Model Compounds. Chem. Lett. 1990; 995-998.

http://dx.doi.org/10.1246/cl.1990.995

[2] Ujiie S, limura K. Thermal Properties and Orientational Behavior of a Liquid-Crystalline Ion Complex Polymer. Macromolecules 1992; 25: 3174-3178. http://dx.doi.org/10.1021/ma00038a024

[3] Collings P. J, Patel J. S, Handbook of Liquid Crystal Research. New York: Oxford University Press 1997.

[4] R. V. Talroze, S. A. Kuptov, T. I. Sycheva, V. S. Bezborodv and N. A. Plate, Order and Liquid Crystalline Phase Behavior of Polyacid-Tertiary Amine Complexes. Macromolecules 1995; 28: 8689-91. http://dx.doi.org/10.1021/ma00129a032

[5] Ujiie S, Furukawa H, Yano $\mathrm{Y}$, Mori A, Oriented glass states formed by ionic liquid-liquid crystals. Thin Solid Films 2006; 509: 185-8.

http://dx.doi.org/10.1016/j.tsf.2005.09.029

[6] Wu J, Ujiie S, Ionic Liquid Crystalline Materials exhibiting Smectic C Phase. Mol. Cryst. Liq. Cryst. 2012; 563: 67-74. http://dx.doi.org/10.1080/15421406.2012.688617

[7] Ujiie S, Takagi S, Sato M, Lamellar Mesophases formed by Thermotropic Liquid Crystalline Ionic Polymer Systems without Mesogenic Units. High Perform. Polym. 1998; 10: 139-46.

http://dx.doi.org/10.1088/0954-0083/10/1/015

[8] Ujiie S, limura K, Formation of Smectic Orientational Order in an Ionic Thermotropic Liquid-Crystalline Side-Chain Polymer. Polym. J. 1993; 25: 347-54 http://dx.doi.org/10.1295/polymj.25.347

[9] Ujiie S, Tanaka $\mathrm{Y}$, and limura K, Thermal and Liquid Crystalline Properties of Liquid Crystalline Polymethacrylates with Ammonium Units and their Non-ionic Family. Polym. Adv. Technol. 2000; 11: 450-5.

http://dx.doi.org/10.1002/1099-

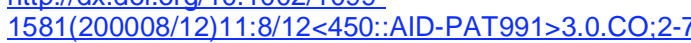

[10] Ujiie S, Yano Y, Thermotropic and Lyotropic Behavior of novel Amphiphilic Liquid Crystals having Hydrophilic 
Poly(ethyleneimine) Units. Chem. Comm. 2000; 79-80. http://pubs.rsc.org/en/content/articlelanding/2000/cc/a907765 $\mathrm{k}$

[11] Ujiie S, Yano $Y$, Liquid Crystalline Properties and Orientational Structure of Binary Systems Built from Poly(vinyl alcohol) and Amphiphilic Compound. Mol. Cryst. Liq. Cryst. 2000; 347: 265-72.

http://dx.doi.org/10.1080/10587250008024848
[12] Kadokawa J, Hirohama K, Mine S, Kato T, Yamamoto K, Facile Preparation of Chitin/Cellulose Composite Films Using Ionic Liquids. J. Polym. Environ. 2012; 20: 37-42. http://dx.doi.org/10.1007/s10924-011-0331-3 